\title{
Microbial Contamination and Antimicrobial Resistance in Use of Ophthalmic Solutions at the Department of Ophthalmology, Jimma University Specialized Hospital, Southwest Ethiopia
}

\author{
Lemlem Tamrat, ${ }^{1}$ Yeshigeta Gelaw, ${ }^{2}$ Getenet Beyene, ${ }^{3}$ and Addisu Gize $(\mathbb{D})^{4}$ \\ ${ }^{1}$ Department of Ophthalmology, Saint Paul's Hospital Millennium Medical College, Addis Ababa, Ethiopia \\ ${ }^{2}$ Department of Ophthalmology, College of Medicine and Health Sciences, Bahir Dar Universisty, Bahir Dar, Ethiopia \\ ${ }^{3}$ Department of Laboratory Science, Faculty of Health and Medical Sciences, Jimma University, Jimma, Ethiopia \\ ${ }^{4}$ Department of Microbiology, St. Paul's Hospital Millennium Medical College, Addis Ababa, Ethiopia
}

Correspondence should be addressed to Addisu Gize; konjoaddisu@gmail.com

Received 25 December 2018; Revised 9 March 2019; Accepted 11 March 2019; Published 15 April 2019

Academic Editor: Jorge Garbino

Copyright (c) 2019 Lemlem Tamrat et al. This is an open access article distributed under the Creative Commons Attribution License, which permits unrestricted use, distribution, and reproduction in any medium, provided the original work is properly cited.

\begin{abstract}
Background. Eye drops are most frequently used medications in ophthalmology. The carriage of pathogenic organisms to eyes through the agency of eye drops has presented a serious problem for several decades. The objective of this study was to determine the magnitude of contamination and pattern of antimicrobial resistance of in-use ophthalmic solutions. Method. A cross-sectional study was conducted at the Department of Ophthalmology, Jimma University Specialized Hospital (JUSH), Southwest Ethiopia, from June to December 2015. Samples from all ophthalmic solutions from outpatient department, operation theaters, and wards after an average duration of use of two weeks were taken. Samples were cultured and organisms were identified; antimicrobial susceptibility testing was performed using standard microbial identification techniques. The data were analyzed using SPSS software. Chi-square test was done and associations were taken as significant if $P<0.05$. Result. The rate of contamination of eye drops in the study setup was found to be 51/70 (72.8\%). Frequency of contamination of eye drops found was to be statistically associated with the duration of use of eye drops. Contaminations of eye drops were high among patients who self-administer the medications and those individuals who apply the medication less frequently. Tips of the bottles were more often contaminated than the content of the eye drop. Majority of both Gram-positive and Gram-negative organisms were sensitive for most of the broad-spectrum antibiotics; however, there were a significant number of Gram-negative organisms resistant to almost all antibiotics used. Conclusion. There is high rate of contamination of eye drops in the setup $(72.8 \%)$. Duration of use of eye drops is a significant factor associated with contamination. Knowing duration time of each container and patient education on eye drop administration technique are mandatory.
\end{abstract}

\section{Background}

Topical eye drop medications are the most frequently used medications in Ophthalmology. It can be prepared locally or can be bought from market. Commonly used eye drops include tetracaine, mydriatics, miotics, $\beta$-blockers, lubricants, and steroids $[1,2]$. Eye drops are presumed sterile when first opened. Contaminated eye drops used for both diagnostic and therapeutic purposes are a potential cause of ocular infections. Bacterial ocular infections such as keratitis
[2] and endophthalmitis can be caused by contaminated eye droppers [3]. The published contamination rate of in-use eye drops varies widely from $0.07 \%$ to $35.8 \%[2,4]$.

Eye drop contamination increases with the duration of use $[1,5]$. A dramatic increase in eye drop contamination appeared in many studies proportional to the use of frequencies [1,6-8]. Vials containing an antimicrobial agent were less likely to be contaminated than vials without antimicrobials $[9,10]$. Poor technique in administering the drops is another risk factor for contamination, especially if 
patients are self-administering their drugs [11, 12]. Elderly patients, with poor vision, coordination, and difficulty in fine grasping, which may lead to fingers touching the tip of the container or touching their eyes or skin with dropper, may again contaminate the container $[5,13]$. Contact with fingers or lids, ciliaries, conjunctiva, or cornea is the possible cause of contamination even if instilled by healthcare professionals. The bottle tips are more often contaminated than the solution $[5,14]$.

Commonly identified Gram-positive bacteria in different reports include coagulase-negative Staphylococci [15], Corynebacterium species, Propionibacterium species, as well as Staphylococcus aureus, Bacillus species, Micrococcus species, and Enterobacter species [2, 16]. Potentially pathogenic Gram-negative organisms were significantly isolated from all medication sites than Gram-positive organisms. Commonly identified ones are Serratia marcescens, Enterobacter aerogenes, Pseudomonas, and Proteus [9, 17]. There are some studies noting high frequencies of fungal contamination in the caps of the eye drop products $[2,18]$. Apart from the risk of infection, bacterial contamination of eye drops may alter the $\mathrm{pH}$ of the solution and therefore reduce the efficacy of the drug $[10,19]$. Even though medication contamination is clinically important, little attention has been paid to the proper and aseptic method of preparation of eye drops in this specialized teaching hospital and limited studies exist in the country in general $[15,17]$. Therefore, the aims of this study were to determine the magnitude and pattern of microbial contamination of in-use eye drops at the Department of Ophthalmology, Jimma University, Ethiopia.

\section{Materials and Methods}

The study was a cross-sectional hospital-based study which was undertaken from June to December 2015. All multidose eye drop vials in use by patients admitted in the outpatient department, operation theaters, and eye ward during the study period were taken for the study after an average use for two weeks. For the purpose of this study, commonly used eye drops were labeled with its first date of opening preparation. The number of days since the bottles were opened and the visual appearance of the bottles were noted on the data collecting format. A check list was used to record the sociodemographic information and the reason for the use of eye drops.

\subsection{Sample Size and Sampling Technique. Sample size was} calculated based on the single population proportion formula, considering the prevalence rate of $6 \%$ from the previous study conducted in Kenya [3]. Expected margin of error $(d)$ was 0.05 , and confidence interval $(z)$ was $95 \%$. A total of 70 eye drop vials were used consecutively consenting patients, who attended the Department of Ophthalmology, Jimma University, Ethiopia.

2.2. Specimen Collection, Transportation, and Microbial Isolation. All eye drop bottle samples were taken to the Department of Microbiology, Jimma University Specialized Hospital (JUSH), and were inoculated on the same day in order to minimize the effects of storage time and the clinical condition as far as possible. For the dropper tip, a sterile cotton swab moistened in sterile normal saline was used before wiping the nozzle tip of the eye drop containers and then inoculated onto blood agar plate (BAP), mannitol salt agar (MSA), MacConkey, chocolate agar, and Sabouraud Dextrose. For the residual eye drop, after cleaning the tip with $70 \%$ alcohol, the bottle was shaken well and one drop of the solution was directly inoculated by inverting the container on blood agar, mannitol salt agar, MacConkey, chocolate agar, and Sabouraud Dextrose Agar and then spread across the plates with loop. Blood agar was used for isolation of both Gram-positives and Gram-negatives. mannitol salt agar was used for isolation of Gram-positive bacteria particularly Staphylococci species and McConkey agar was used for Gram-negatives, and chocolate agar for the Haemophilus species. For isolation of the fungus, Sabouraud Dextrose Agar (SDA) plates was used.

The BAP, MSA, and McConkey agar were incubated at $37^{\circ} \mathrm{C}$ for 24 hours. The chocolate plates were incubated at $37^{\circ} \mathrm{C}$ in $\mathrm{CO}_{2}$. The SDA plates were incubated at $30^{\circ} \mathrm{C}$ for up to 7 days and evaluated for growth on days 1, 5, and 10. All media and antibiotics were purchased and used from Oxoid, UK.

2.3. Bacterial Identification. Bacteria isolates were identified based on Gram reaction, colony characterization, and biochemical test. Biochemical tests, namely, indole, citrate, oxidase, $\mathrm{H}_{2} \mathrm{~S}$ production, KIA, lysine decarboxylase, lactose fermentation, urea hydrolysis, and gas production, were performed for identification for Gram-negative isolates. Catalase, coagulase test, and haemolysis pattern on blood agar was used for identification of Gram-positive bacteria. Fungal isolates were identified based on colony morphology on SDA and Gram stain [2], and germ tube test was done to isolate Candida spp.

2.4. Antimicrobial Susceptibility Testing (AST). AST for the isolated colonies were done with the Kirby-Bauer disc diffusion method, a recommended method by National Committee for Clinical Laboratory Standards (CLSI) [20].

With an inoculating loop, colonies were transferred into a tube containing 4 to $5 \mathrm{ml}$ of a suitable normal saline which was incubated at $35^{\circ} \mathrm{C}$ until it achieves the turbidity of the 0.5 McFarland standards (usually 2 to 6 hours). The dried surface of a Müeller-Hinton agar plate was inoculated by streaking the swab over the entire sterile agar surface. The predetermined battery of antimicrobial disc was dispensed onto the surface of the inoculated agar plate. Each antimicrobial disc was pressed down to ensure complete contact with the agar surface. The discs were placed individually no closer than $24 \mathrm{~mm}$ from center to center. The following antibiotic discs were used for antibiotic susceptibility testing. Tetracycline hydrochloride (TE, $30 \mu \mathrm{g})$, penicillin G (P, $10 \mu \mathrm{g})$, erythromycin (E, $15 \mu \mathrm{g})$, vancomycin (VA, $30 \mu \mathrm{g})$, oxacillin $(\mathrm{OX}, 5 \mu \mathrm{g})$, gentamicin $(\mathrm{GN}, 10 \mu \mathrm{g})$, chloramphenicol $(\mathrm{C}, 30 \mu \mathrm{g})$, norfloxacin (NOR, $5 \mu \mathrm{g})$, ciprofloxacin (CIP, $5 \mu \mathrm{g}$ ), and cefuroxime (CXMP, $30 \mu \mathrm{g}$ ). Vancomycin 
TABLE 1: Sociodemographic features and eye drop use versus contamination among patients admitted in the wards at Jimma University the Department of Ophthalmology from June to December 2015.

\begin{tabular}{|c|c|c|c|c|c|}
\hline \multicolumn{2}{|c|}{ Sociodemographic characteristics } & Contaminated $n=19$ & Noncontaminated $n=6$ & Total & $P$ value \\
\hline Age & $\begin{array}{l}<40 \mathrm{yrs} \\
\geq 40 \mathrm{yrs}\end{array}$ & $\begin{array}{c}12(75.0 \%) \\
7(77.8 \%)\end{array}$ & $\begin{array}{l}4(25.0 \%) \\
2(22.2 \%)\end{array}$ & $\begin{array}{l}16(64.0) \\
9(36.0 \%)\end{array}$ & $1.0^{*}$ \\
\hline Sex & $\begin{array}{c}\text { Male } \\
\text { Female }\end{array}$ & $\begin{array}{c}11(73.3 \%) \\
8(80.0 \%) \\
\end{array}$ & $\begin{array}{l}4(26.7 \%) \\
2(20.0 \%)\end{array}$ & $\begin{array}{l}15(60.0 \%) \\
10(40.0 \%)\end{array}$ & $1.00^{*}$ \\
\hline Marriage & $\begin{array}{c}\text { Married } \\
\text { Unmarried }\end{array}$ & $\begin{array}{c}1(68.8 \%) \\
8(88.9 \%)\end{array}$ & $\begin{array}{l}5(31.2 \%) \\
1(11.1 \%) \\
\end{array}$ & $\begin{array}{c}16(64.0 \%) \\
9(36.0 \%)\end{array}$ & $0.364^{*}$ \\
\hline Occupation & $\begin{array}{c}\text { Employed } \\
\text { Unemployed }\end{array}$ & $\begin{array}{c}12(75.0 \%) \\
4(44.4 \%)\end{array}$ & $\begin{array}{l}4(25.0 \%) \\
5(55.6 \%)\end{array}$ & $\begin{array}{c}16(64.0 \%) \\
9(36.0 \%)\end{array}$ & $1.00^{*}$ \\
\hline Education & $\begin{array}{l}\text { Illiterate } \\
\text { Literate }\end{array}$ & $\begin{array}{c}13(92.9 \%) \\
6(54.5 \%)\end{array}$ & $\begin{array}{c}1(7.1 \%) \\
5(45.5 \%)\end{array}$ & $\begin{array}{l}14(56.0 \%) \\
11(44.0 \%)\end{array}$ & $0.056^{*}$ \\
\hline Residence & $\begin{array}{l}\text { Urban } \\
\text { Rural }\end{array}$ & $\begin{array}{c}15(88.2 \%) \\
4(50.0 \%)\end{array}$ & $\begin{array}{l}2(11.8 \%) \\
4(50.0 \%)\end{array}$ & $\begin{array}{l}17(68.0 \%) \\
8(32.0 \%)\end{array}$ & $0.059^{*}$ \\
\hline Technique of drug administration & $\begin{array}{c}\text { Self-administration } \\
\text { Non-self-administration }\end{array}$ & $\begin{array}{c}4(80.0 \%) \\
15(75.0 \%)\end{array}$ & $\begin{array}{l}1(20.0 \%) \\
5(25.0 \%)\end{array}$ & $\begin{array}{l}5(20.0 \%) \\
20(80 \%)\end{array}$ & $1.0^{*}$ \\
\hline Reason of use of eye drops & $\begin{array}{l}\text { Postoperative } \\
\text { Glaucoma } \\
\text { Infection } \\
\text { Lubrication }\end{array}$ & $\begin{array}{c}7(87.5 \%) \\
1(50.0 \%) \\
10(71.4 \%) \\
1(100.0 \%)\end{array}$ & $\begin{array}{l}1(12.5 \%) \\
1(50.0 \%) \\
4(28.6 \%) \\
0\end{array}$ & $\begin{aligned} & 8(32.0 \%) \\
& 2(8.0 \%) \\
& 14(56.0 \%) \\
& 1(4.0 \%) \\
&\end{aligned}$ & 0.09 \\
\hline Frequency of use of eye drops & $\begin{array}{l}<4 \text { times/day } \\
\geq 4 \text { times/day }\end{array}$ & $\begin{array}{c}13(81.2 \%) \\
6(66.7 \%)\end{array}$ & $\begin{array}{l}3(18.8 \%) \\
3(33.3 \%)\end{array}$ & $\begin{array}{c}16(64.0 \%) \\
9(36.0 \%)\end{array}$ & $0.63^{*}$ \\
\hline
\end{tabular}

*Fisher's exact test.

discs were used for only Gram-positives and gentamicin discs only for Gram-negatives.

The plates were inverted and placed in an incubator set to $35^{\circ} \mathrm{C}$ within 15 minutes after the discs were applied. After 18 to 24 hours of incubation, each plate was examined. The diameters of the zones of complete inhibition (as judged by the unaided eye) were measured to the nearest whole millimeter, using sliding calipers or a ruler, which is held on the back of the inverted Petri plate. The sizes of the zones of inhibition were interpreted by referring to Performance Standards for Antimicrobial Susceptibility Testing (NCCLS M100-S12), and the organisms were reported as susceptible, intermediate, or resistant to the agents that have been tested [20]. The quality of the culture media and Gram stain was checked using a standardized reference strain of Escherichia coli (ATCC 25922) and Staphylococcus aureus (ATCC 25923).

Ethical clearance was secured from the Research and Ethical Review Committee of the College of Health Science, Jimma University. Verbal consent was obtained from individual patients owning the eye drops.

\section{Results}

A total of 70 eye drop vials were analyzed, 25 (35.7\%) of the bottles were from patients admitted in the ward during the study period, and $45(64.3 \%)$ were from the outpatient department. Twenty percent $5 / 25$ patients reported that they apply the eye drops by themselves. On the contrary, 20 $(80.0 \%)$ reported that others apply the eye drop for them, and from these, $15(75.0 \%)$ of them were using contaminated eye drops (Fisher's exact value $=1.0)($ Table 1$)$.
Most of the eye drops used in the department were mydriatics, tetracaine, and antibiotics 26 (37.1\%), 18 (25.7\%), and $14(18.1 \%)$, respectively (Figure 1 ).

Contamination was found to be high in those vials without antibiotics but this was not statistically significant $\left(X^{2}=0.281, P\right.$ value $\left.=0.569\right)$. The pip of the eye bottle was more often contaminated than the drop (31 (60.8\%) versus 2 (3.9\%)).

Of the 70 eye drops, $51(72.9 \%)$ were contaminated with one or more organisms. Most of the eye drops 58 (82.9\%) were commercially bought. Forty-one $(58.6 \%)$ of the eye drop vials were used by many patients, from these, 29 (70.7\%) were contaminated. On the contrary, 29 (41.4\%) of the eye drops were used by single patient and, from these, 22 $(75.9 \%)$ of them were found to be contaminated. The majority of the eye drops, 41 (58.6\%), were in use for 2-4 weeks, and $28(40.0 \%)$ of them were in use for more than a month. Duration of use of eye drops and eye drop contamination were found to have a significant association (Chisquare $=4.462, P$ value $=0.035)($ Table 2$)$.

Of the 51 eye bottles contaminated, $43 / 51$ (84.3\%) of the bottles were bacteria, 28/51 (54.9\%) of the bottles were fungus, and 20/51 (39.2\%) were contaminated by both bacteria and fungus.

Staphylococcus aureus is the most common Grampositive bacteria isolated followed by Bacillus species constituting 17 (60.7\%) and 5 (17.9\%), respectively. Proteus species and Klebsiella species were the most common Gramnegative isolates (Table 3 ).

The intermediate sensitive and resistant organisms were grouped under resistant category as it is listed in Table 4. All Gram-positive organisms found to be resistant to erythromycin and sensitive for ciprofloxacin. Most of 


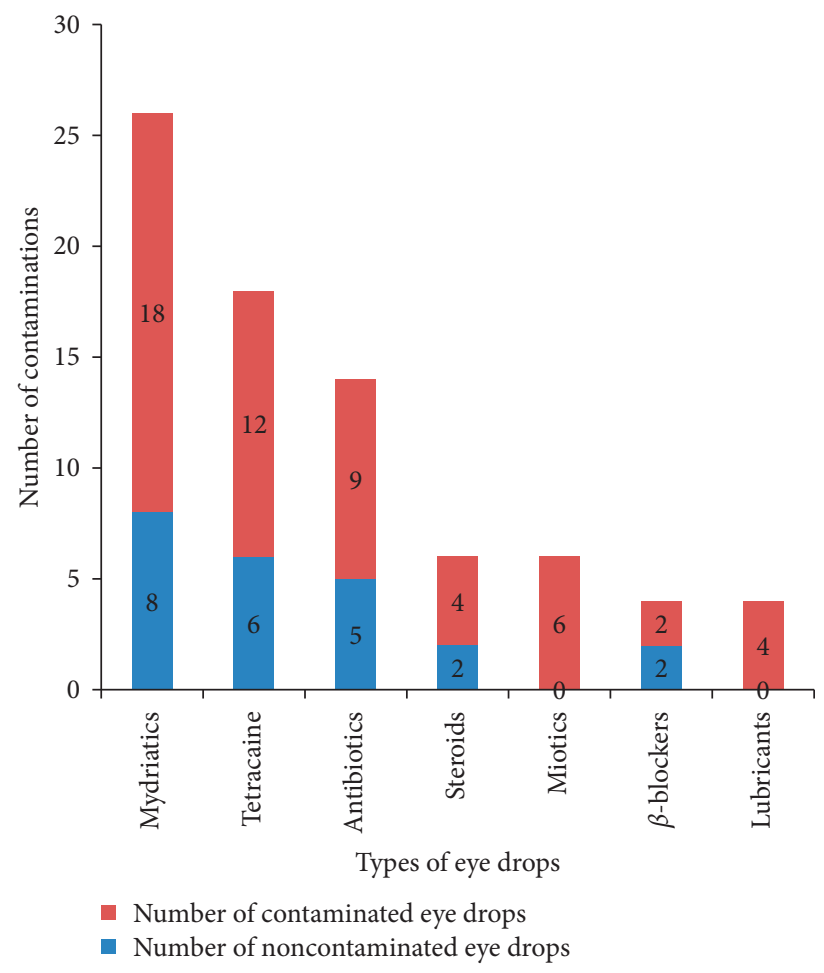

Figure 1: Types and number of contaminated commonly used eye drops contamination at Department of Ophthalmology, Jimma University from June to December 2015.

TABle 2: Features of eye drops used in the Department of Ophthalmology, Jimma University, from June to December 2015.

\begin{tabular}{|c|c|c|c|c|c|}
\hline Eye drop characteristics & Contaminated $n=51$ & Noncontaminated $n=19$ & Total & $X^{2}$ & $P$ value \\
\hline $\begin{array}{l}\text { Place of use } \\
\text { Wards } \\
\text { OPD } \\
\text { OR }\end{array}$ & $\begin{array}{c}18(75.0 \%) \\
25(73.5 \%) \\
8(66.7 \%)\end{array}$ & $\begin{array}{l}6(25.0 \%) \\
9(26.5 \%) \\
4(33.3 \%)\end{array}$ & $\begin{array}{l}24(34.3 \%) \\
34(48.6 \%) \\
12(17.1 \%) \\
\end{array}$ & 0.29 & 0.86 \\
\hline $\begin{array}{l}\text { Expiry date } \\
\text { Not expired } \\
\text { Expired } \\
\text { Not marked }\end{array}$ & $\begin{array}{l}23(45.1 \%) \\
16(31.4 \%) \\
12(23.5 \%) \\
\end{array}$ & $\begin{array}{c}10(52.6 \%) \\
8(42.1 \%) \\
1(5.3 \%) \\
\end{array}$ & $\begin{array}{l}33(47.1 \%) \\
24(34.3 \%) \\
13(18.6 \%) \\
\end{array}$ & 3.11 & 0.21 \\
\hline $\begin{array}{l}\text { Duration of use } \\
\leq 4 \text { weeks } \\
>4 \text { weeks }\end{array}$ & $\begin{array}{l}26(63.4 \%) \\
25(86.2 \%)\end{array}$ & $\begin{array}{c}15(36.6 \%) \\
4(13.8 \%)\end{array}$ & $\begin{array}{l}41(58.6 \%) \\
29(41.4 \%)\end{array}$ & 4.46 & 0.04 \\
\hline $\begin{array}{l}\text { Preparation of drops } \\
\text { Locally made } \\
\text { Commercially bought }\end{array}$ & $\begin{array}{l}11(91.7 \%) \\
40(69.0 \%) \\
\end{array}$ & $\begin{array}{c}1(8.3 \%) \\
18(31.0 \%) \\
\end{array}$ & $\begin{array}{l}12(17.1 \%) \\
58(82.9 \%) \\
\end{array}$ & 2.59 & 0.11 \\
\hline $\begin{array}{l}\text { Use of eye drops } \\
\text { Single patient use } \\
\text { Many patient use }\end{array}$ & $\begin{array}{l}22(75.9 \%) \\
29(70.7 \%) \\
\end{array}$ & $\begin{array}{c}7(24.1 \%) \\
12(29.3 \%) \\
\end{array}$ & $\begin{array}{l}29(41.4 \%) \\
41(58.6 \%) \\
\end{array}$ & 0.23 & 0.63 \\
\hline $\begin{array}{l}\text { Appearance } \\
\text { Clean } \\
\text { Dirty }\end{array}$ & $\begin{array}{l}48(71.6 \%) \\
3(100.0 \%)\end{array}$ & $\begin{array}{c}19(28.4 \%) \\
0\end{array}$ & $\begin{array}{c}67(95.7 \%) \\
3(5.3 \%)\end{array}$ & & \\
\hline
\end{tabular}

OPD = outpatient department; OR = operation room.

the Gram-positive organisms were resistant to tetracycline (TTC) and penicillin and sensitive for chloramphenicol (CAF) and gentamicin. Most of the Gram-negative isolates were sensitive for gentamicin and chloramphenicol and resistant to vancomycin and oxacillin. It was also found out that one species of Klebsiella and one species of Pseudomonas were resistant for all the antibiotics tested (Table 4). 
TABle 3: Gram-positive and Gram-negative bacteria species cultured from the contaminated eye drop bottles at the Department of Ophthalmology, Jimma University from June-December 2015.

\begin{tabular}{|c|c|c|}
\hline & Organisms isolated & Number (\%) \\
\hline \multirow{5}{*}{ Gram-positive bacteria } & Staphylococcus aurous (CPS) & $17(60.7 \%)$ \\
\hline & Bacillus spp & $5(17.9 \%)$ \\
\hline & Staphylococcus saprophyticus (CNS) & $3(10.7 \%)$ \\
\hline & Staphylococcus epidermidis & $2(7.1 \%)$ \\
\hline & Corynebacterium spp & $1(3.6 \%)$ \\
\hline \multirow[t]{6}{*}{ Total } & & 28 \\
\hline & Proteus spp & $5(17.9 \%)$ \\
\hline & Klebsiella spp & $5(17.9 \%)$ \\
\hline & Pseudomonas spp & $2(7.1 \%)$ \\
\hline & Serratia spp & $2(7.1 \%)$ \\
\hline & Morganella morganii & $2(7.1 \%)$ \\
\hline \multirow[t]{6}{*}{ Gram-negative bacteria } & Citrobacter spp & $2(7.1 \%)$ \\
\hline & E. coli & $2(7.1 \%)$ \\
\hline & Edwardsella & $2(7.1 \%)$ \\
\hline & Providencia & $2(7.1 \%)$ \\
\hline & Salmonella spp & $2(7.1 \%)$ \\
\hline & Acinetobacter spp & $2(7.1 \%)$ \\
\hline Total & & 28 \\
\hline
\end{tabular}

\section{Discussion}

In this study, contamination occurred in $51 / 70(72.8 \%)$ of eye bottles used in the department. This is very high when compared to the results of other literature; for example, a study done in USA [5] and Kenya [3] reported 28\% and 6\% of contamination, respectively. This could be explained by poor handling, care, and follow-up given to eye drops used in the department. In line with other literatures $[5,17]$, the duration of use of eye drops was significantly associated with the contamination of eye drops $(P<0.05)$. The explanation could be the prolonged duration of use, which might increase the chance of contamination. From all kinds of eye drops analyzed, all miotics (pilocarpine) and lubricants were found to be contaminated. This is similar with a study done in Iran where pilocarpine is the highest rate of contamination than other eye drops [2]; this can be due to less common use of these eye drops, especially for communal use, which made them to be used for long time so that they will be exposed for contamination. It was also shown that contaminations of steroids were higher than that in another study [1]. Eye drop vials with antibiotics were found to be less frequently contaminated than vials without antibiotics. This might be due to the self-sterilizing effect of antibiotics. This finding is consistent with the other literature [9]. Unexpectedly, eye drops in use for a single patient were found to be more frequently contaminated than those in use for many patients. This could be due to negligence of patients to practice the instruction and the poor general hygienic condition of patients.

Self-administration was another issue related to contamination; when patients self-administer their drugs, they may inadvertently touch the eye lids with the tip and also with their own finger and cloths. The higher contamination rate on those eye drops in use less frequently ( $<4$ times/day) contradicts the finding of one study done in the UK, which reported that eye drops used more frequently are at risk of contamination [9]. This might be related to the duration of use of these drugs, as drugs which are applied less frequently tend to be used for long time and thus they can be contaminated.

The most common Gram-positive organisms recovered were Staphylococcus aureus 17 (60.7\%) and Bacillus species 5 (17.9\%). This is comparable to other literatures [5]. A study done in the UK showed that $S$. aureus was the most common contaminant with percentage occurrence of $4.5 \%$ [9]. A study done in Kenya showed that 4/6 (66.7\%) of the identified organisms were Gram-positive [3]. In this study, most of the Gram-positive organisms recovered were part of the normal flora of the conjunctiva. Normal resident flora of the conjunctiva and eye lids includes Gram-positive bacteria, including S. aureus, Corynebacterium species, Propionibacterium species, Bacillus species, Micrococcus species, and Enterobacter species [4, 5].

In this study, we found a high rate of contamination of ocular medications, particularly with potentially pathogenic Gram-negative organisms such as Proteus species, Klebsiella species, Pseudomonas, Escherichia coli, Serratia species, etc., that are not part of usual eye flora. Proteus spp. were present in 6/27 eye bottles, and Klebsiella species were seen in 4/27 vials in this study. Similar to many studies done in USA [1] we found Gram-negative organisms, specially Proteus species, Serratia, and Pseudomonas species, in a large number of eyedrops. This might be related to the poor technique and supervision of local eye drop preparation in the department and poor handling and use of eye drops by patients in the ward.

Majority of both Gram-positive and Gram-negative organisms were sensitive for most of the broad-spectrum antibiotics; however, there were a significant number of Gram-negative organisms found, which were resistant to almost all antibiotics used. This indicates that there exist 


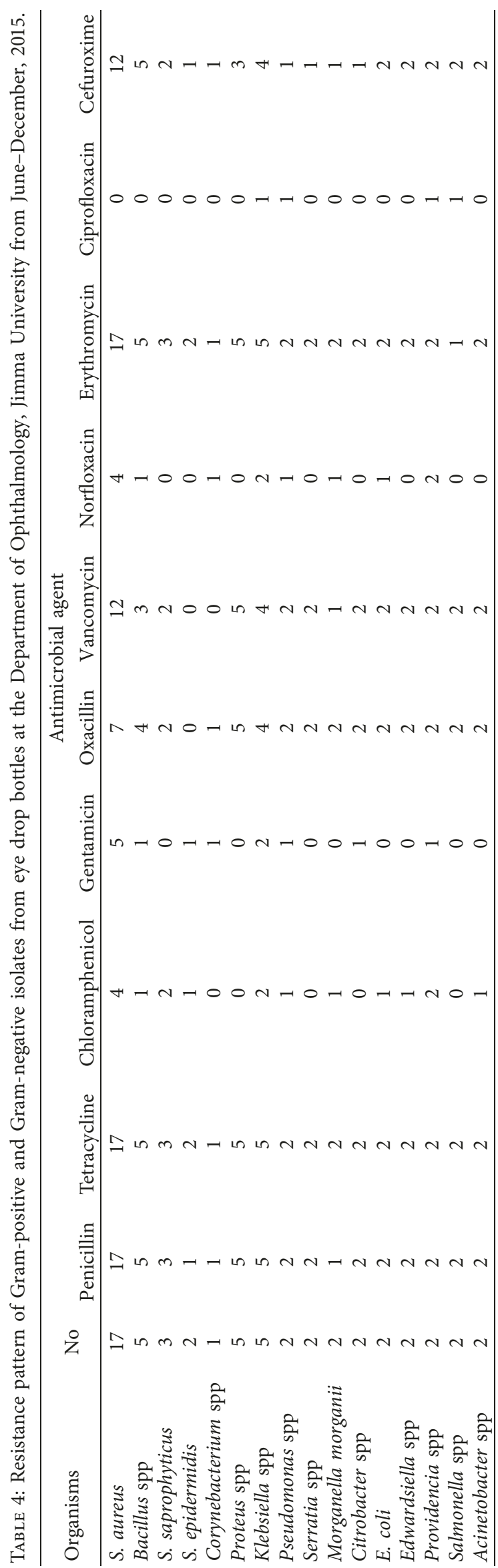


pathogenic organisms nonresponsive to antibiotics in eye drop vials, which might contribute to ocular infection and also cross contamination of patients who share eye drop vials.

Fungus was isolated in 28 eye drop vials. This extent of contamination with fungus is not a small number for this setup; it is difficult to compare this to other studies because there are no literature studies on this issue.

\section{Conclusions}

There is high rate of contamination of eye drops in this setup. Gram-negative organisms more often contaminate the tip of eye drop rather than the drop. Most eye drop contaminants were sensitive for chloramphenicol, gentamicin, norfloxacin, and ciprofloxacin. Multiple drug resistance was seen among Klebsiella spp and Pseudomonas spp.

Marking the first date of opening on each container to know duration of time is mandatory so that it can be replaced on a regular basis. Patient education on eye drop administration technique, handling, and additionally safe technique in preparation of local eye drops needs to be considered by the responsible health professionals who work in this area.

\section{Abbreviations}

AST: Antimicrobial susceptibility testing

BAP: Blood agar plate

CAF: Chloramphenicol

CLSI: Clinical laboratory standards institutes

JUSH: Jimma University Specialized Hospital

MSA: Mannitol salt agar

SDA: Sabouraud Dextrose Agar plates

SPP: Species

TTC: Tetracycline.

\section{Data Availability}

The data used to support this study are available from the corresponding author upon request.

\section{Ethical Approval}

The proposed study was approved by the Research and Ethics Committee of Jimma University, College of Medicine and Health Science, who approved this work concerning the ethical issues.

\section{Disclosure}

The funder had no role in study design, data collection and analysis, decision to publish, or preparation of the manuscript.

\section{Conflicts of Interest}

The authors declare that they have no conflicts of interest.

\section{Authors' Contributions}

LT and AG were involved in study conception, data analysis, and drafting of the manuscript. YG and GB critically reviewed the manuscript for intellectual content. All authors read, edited, and approved the manuscript.

\section{Acknowledgments}

The principal author would like to thank Mr. Tamrat Tigabu and Mr. Muluken Awulachew, who gave moral support in writing this paper, and Mrs. Himanot Tassew for her professional support to make this study a real one. The authors greatly acknowledge the Department of Ophthalmology, Jimma University, Ethiopia, for approving this review concerning the ethical issues and for its financial support. The authors also would like to thank the data collectors for their commitment during data collection. This research work was financed by Jimma University, Ethiopia.

\section{References}

[1] D. H.-K. Jokl, G. P. Wormser, N. S. Nichols, M. A. Montecalvo, and C. L. Karmen, "Bacterial contamination of ophthalmic solutions used in an extended care facility," British Journal of Ophthalmology, vol. 91, no. 10, pp. 1308-1310, 2007.

[2] M. Feghhi, A. Zarei Mahmoudabadi, and M. Mehdinejad, "Evaluation of fungal and bacterial contaminations of patientused ocular drops," Medical Mycology, vol. 46, no. 1, pp. 17-21, 2008.

[3] M. M. Nentwich, K. H. M. Kollmann, J. Meshack, D. R. Ilako, and U. C. Schaller, "Microbial contamination of multi-use ophthalmic solutions in Kenya," British Journal of Ophthalmology, vol. 91, no. 10, pp. 1265-1268, 2007.

[4] C. Raynaud, H. Laveran, D. Rigal, and P. Bonicel, "Bacterial contamination of eyedrops in clinical use," Journal Français d'Ophtalmologie, vol. 20, no. 1, pp. 17-24, 1997.

[5] O. Geyer, E. J. Bottone, S. M. Podos, R. A. Schumer, and P. A. Asbell, "Microbial contamination of medications used to treat glaucoma," British Journal of Ophthalmology, vol. 79, no. 4, pp. 376-379, 1995.

[6] V. T. Yin, D. J. Weisbrod, K. T. Eng et al., "Antibiotic resistance of ocular surface flora with repeated use of a topical antibiotic after intravitreal injection," JAMA Ophthalmology, vol. 131, no. 4, pp. 456-461, 2013.

[7] E. Milder, J. Vander, C. Shah, and S. Garg, "Changes in antibiotic resistance patterns of conjunctival flora due to repeated use of topical antibiotics after intravitreal injection," Ophthalmology, vol. 119, no. 7, pp. 1420-1424, 2012.

[8] M. R. Fazeli, H. B. Nejad, H. Mehrgan, and L. Elahian, "Microbial contamination of preserved ophthalmic drops in outpatient departments: possibility of an extended period of use," DARU Journal of Pharmaceutical Sciences, vol. 12, no. 4, pp. 151-155, 2004.

[9] M. Q. Rahman, D. Tejwani, J. A. Wilson, I. Butcher, and K. Ramaesh, "Microbial contamination of preservative free eye drops in multiple application containers," British Journal of Ophthalmology, vol. 90, no. 2, pp. 139-141, 2006.

[10] R. Noecker, "Effects of common ophthalmic preservatives on ocular health," Advances in Therapy, vol. 18, no. 5, pp. 205215, 2001.

[11] J. C. Ginés, M. Samudio, N. Fariña et al., "Microbial contamination of eye drops used by patients in an outpatient clinic of ophthalmology," Memorias del Instituto de Investigaciones en Ciencias de la Salud, vol. 10, no. 2, pp. 38-46, 2012. 
[12] R. Jalali, F. Zinolabedini, M. Moradi, and N. Dibazar, "Bacterial contamination rate of eyedrops: comparison of a hospital and a private outpatient center in Kermanshah, Iran," Insight (American Society of Ophthalmic Registered Nurses), vol. 29, no. 3, pp. 12-14, 2004.

[13] B. Teuchner, J. Wagner, N. E. Bechrakis, D. Orth-Höller, and M. Nagl, "Microbial contamination of glaucoma eyedrops used by patients compared with ocular medications used in the hospital," Medicine, vol. 94, no. 8, p. e583, 2015.

[14] P. J. Clark, B. Ong, and C. B. Stanley, "Contamination of diagnostic ophthalmic solutions in primary eye care settings," Military Medicine, vol. 162, no. 7, pp. 501-506, 1997.

[15] A. Tsegaw, A. Tsegaw, T. Abula, and Y. Assefa, "Bacterial contamination of multi-dose eye drops at ophthalmology department, university of Gondar, northwest Ethiopia," Middle East African Journal of Ophthalmology, vol. 24, no. 2, pp. 81-86, 2017.

[16] S. Modarres, A. Lasheii, and N. N. Oskoii, "Bacterial etiologic agents of ocular infection in children in the Islamic Republic of Iran," Eastern Mediterranean Health Journal, vol. 4, no. 1, pp. 44-49, 1998.

[17] Y. Porges, L. Rothkoff, J. Glick, and S. Cohen, "Sterility of glaucoma medications among chronic users in the community," Journal of Ocular Pharmacology and Therapeutics, vol. 20, no. 2, pp. 123-128, 2004.

[18] S. Kyei, D. France, and K. Asiedu, "Microbial contamination of multiple-use bottles of fluorescein ophthalmic solution," Clinical and Experimental Optometry, vol. 102, no. 1, pp. 30-34, 2019.

[19] P. D. Freeman and M. Y. Kahook, "Preservatives in topical ophthalmic medications: historical and clinical perspectives," Expert Review of Ophthalmology, vol. 4, no. 1, pp. 59-64, 2009.

[20] Clinical and Laboratory Standards Institute, Performance Standards for Antimicrobial Susceptibility Testing, Clinical and Laboratory Standards Institute, Vol. 31, Wayne, PA, USA, 2011. 


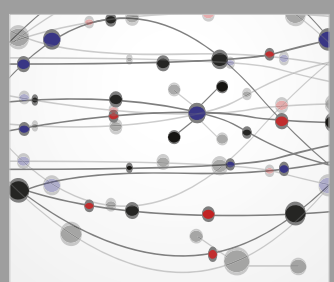

The Scientific World Journal
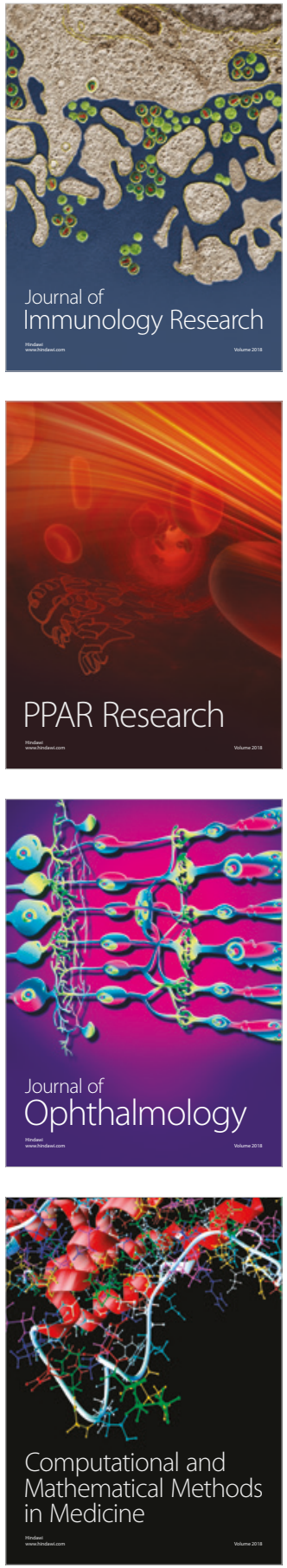

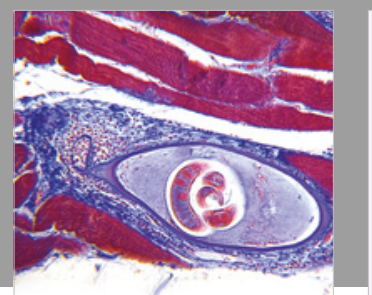

Gastroenterology Research and Practice

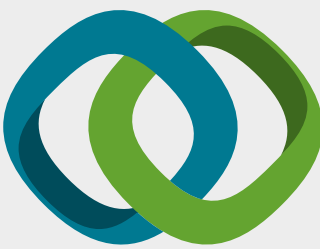

\section{Hindawi}

Submit your manuscripts at

www.hindawi.com
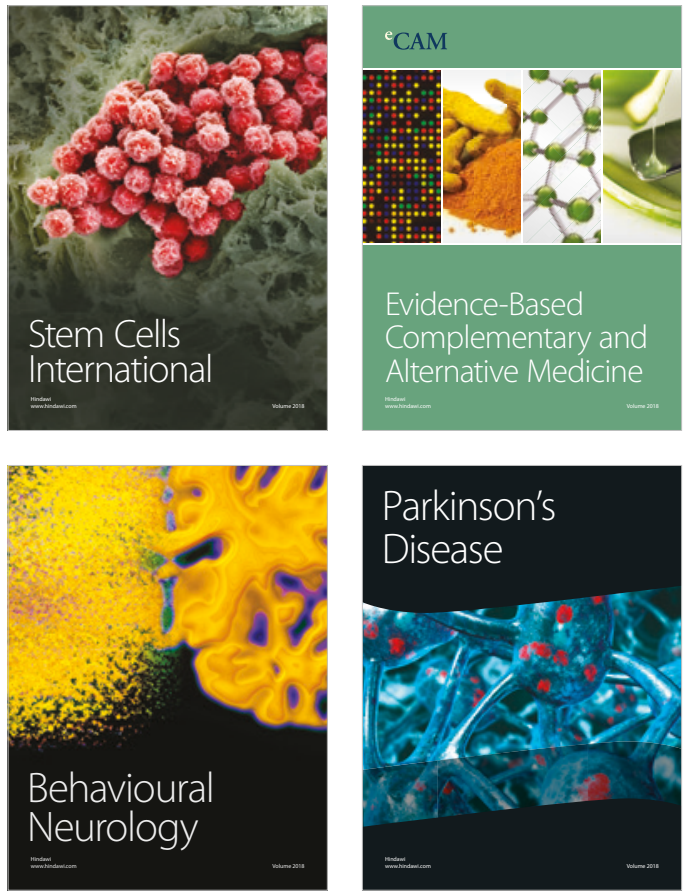

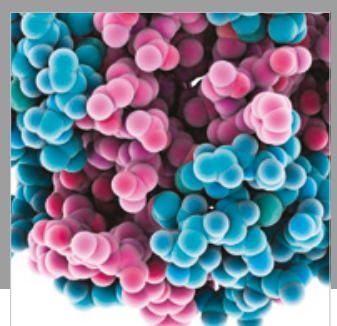

ournal of

Diabetes Research

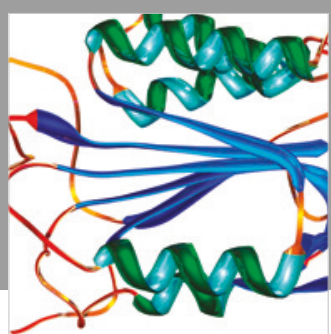

Disease Markers
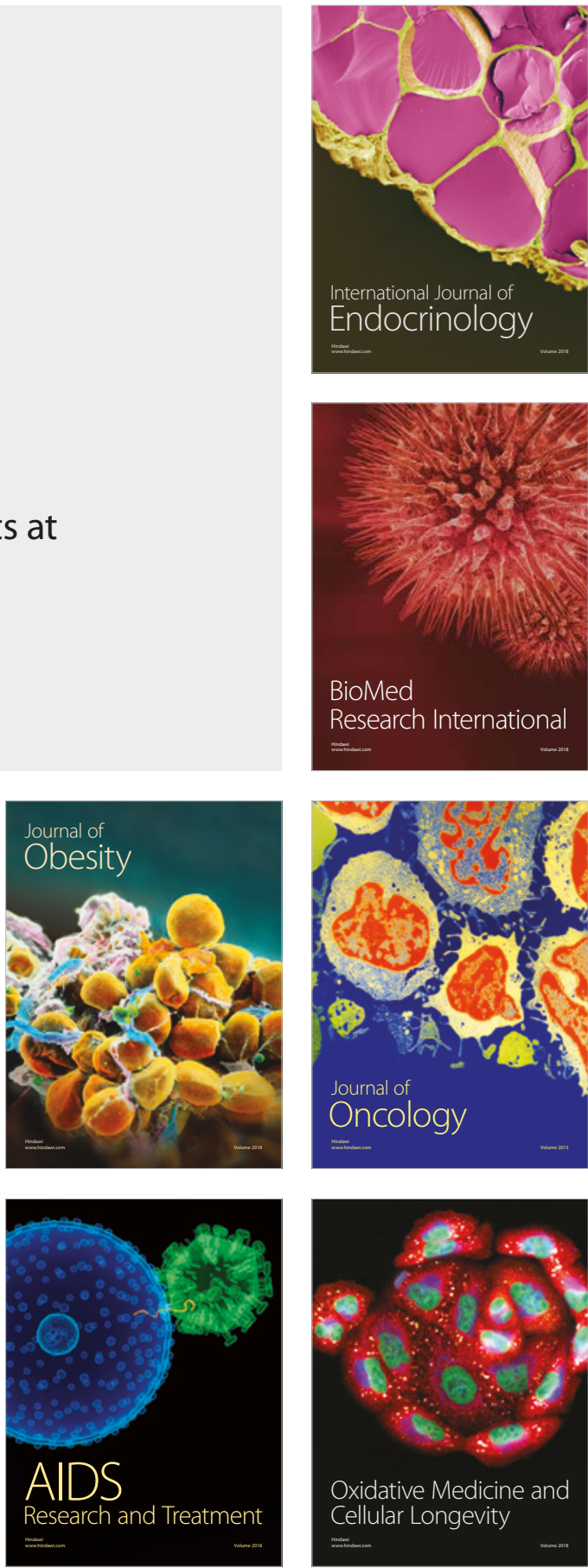